\title{
DISCURSO PEDAGÓGICO Y DEFENSA DEL MAGISTERIO EN RUFINO CARPENA MONTESINOS ${ }^{1}$
}

DOI: http://dx.doi.org/10.1590/2236-3459/60932

\author{
Bernat Sureda Garcia \\ Universidad de las Islas Baleares, España.
}

Sara González Gómez

Universidad de las Islas Baleares, España.

\section{$\cos 80$}

\begin{abstract}
Resumen maestro Rufino Carpena Montesinos, personaje relevante en la historia de la educación española, a través del estudio de sus artículos, y, por otro, analizar su revista, Educacionista, una publicación constituyen un ejemplo paradigmático de cómo la prensa jugó un papel fundamental labor docente y prestigiando la profesión. Educacionista, fotografía.

\section{DISCURSO PEDAGÓGICO E DEFESA DO MAGISTÉRIO EM RUFINO CARPENA MONTESINOS}

El objetivo fundamental de este trabajo es, por un lado, estudiar el discurso pedagógico del publicación escolar editada durante los años 1912 y 1913 en Llucmajor/Mallorca, España. Los contenidos escritos y visuales, con una amplia muestra de fotografías, que presenta esta en la difusión de las actividades desarrolladas en el seno de la escuela, dando visibilidad a la

Palabras-clave: magisterio, identidad profesional, prensa pedagógica, Rufino Carpena,

\section{Resumo}

O objetivo fundamental deste trabalho é, por um lado, estudar o discurso pedagógico do professor Rufino Carpena Montesinos, personagem relevante na história da educação na Espanha, pelo estudo dos seus artigos, e, por outro lado, analisar a revista Educacionista, uma publicação

\footnotetext{
${ }^{1}$ Este trabajo se ha realizado en el marco del proyecto EDU2014-52498-C2-2-P titulado La fotografía publicada como representación de los cambios y las continuidades en la cultura escolar (1900-1970), financiado en el programa estatal de fomento de la investigación científico y técnica de excelencia, subprograma estatal de generación del conocimiento, en la convocatoria del 2014. Asimismo, constituye una ampliación de la comunicación presentada en las II Jornadas de estudio sobre prensa pedagógica, celebradas en Salamanca del 15 al 17 de octubre de 2015, y publicada en Sureda y González (2015).
} 
escolar editada durante os anos de 1912 e 1913 em Llucmajor/Mallorca, España. Os conteúdos escritos e visuais que esta publicação apresenta, com uma ampla amostra fotográfica, constituem um exemplo paradigmático do modo como a imprensa assumiu um papel fundamental na difusão das atividades desenvolvidas no interior da escola dando visibilidade ao trabalho docente e prestigiando a profissão.

Palavras-chave: magistério, identidade profissional, imprensa pedagógica, Rufino Carpena, Educacionista, fotografia.

\title{
PEDAGOGICAL DISCOURSE AND THE DEFENCE OF TEACHING IN RUFINO CARPENA MONTESINOS
}

\begin{abstract}
The main aim of this paper is firstly to study the pedagogical discourse of the teacher Rufino Carpena Montesinos, an important figure in the history of Spanish education, by analysing his articles. Secondly, the paper looks at his magazine, Educacionista, a school publication he edited in 1912 and 1913 in Llucmajor/Majorca, Spain. The writing and visual contents, a wide selection of photographs, in the magazine are a paradigmatic example of how the press played an essential role in promoting the activities undertaken at the school, providing visibility to the work of teaching and honouring the profession.

Key-words: teaching, professional identity, pedagogical press, Rufino Carpena, Educacionista, photography.

\section{DISCOURS PEDAGOGIQUE ET DEFENSE DU METIER D'INSTITUTEUR CHEZ RUFINO CARPENA MONTESINOS}

Résumé

L'objectif fondamental de ce travail est, d'une part, l'étude du discours pédagogique de l'instituteur Rufino Carpena Montesinos, personnage important dans l'histoire de l'éducation en Espagne, à travers l'étude de ses articles et, d'autre part, l'analyse de sa revue, Educacionista, une publication scolaire éditée durant les années 1912 et 1913 à Llucmajor/Majorque, Espagne. Les contenus écrits et visuels, parmi lesquels de nombreuses photographies, de cette publication constituent un exemple paradigmatique du rôle fondamental de la presse dans la diffusion des activités développées au sein de l'école, dotant ainsi la tâche des enseignants d'une plus grande visibilité et donnant à la profession un certain prestige.

Mots-clé: métier d'instituteur, identité professionnelle, presse pédagogique, Rufino Carpena, Educacionista, photographie. 


\section{Introducción}

[ n 1839 se creó en Madrid la primera Escuela Normal destinada a la formación de Maestros. Su primer director, Pablo Montesino, defendía por primera vez una formación específica para los que quisieran dedicarse a la enseñanza. Se aspiraba a consolidar un modelo de nuevos profesionales capacitados para aplicar las nuevas ideas pedagógicas basadas en Rousseau y desarrolladas por educadores como Pestalozzi.

Los maestros titulados en las diversas Escuelas Normales que se fueron creando por todas las provincias españolas fueron, poco a poco, buscando consolidar su identidad profesional, la defensa de sus intereses y el reconocimiento de la dignidad de sus funciones. Para conseguirlo resultaba fundamental, por un lado, adquirir presencia social y, por otro, capacidad de influencia. Para ello, a partir del Sexenio Revolucionario (18681874), y durante la Restauración monárquica (1875-1923), los maestros se fueron agrupando por toda España en asociaciones locales o provinciales, constituyéndose durante estas décadas un elevado número de ellas (Terrón, 1987).

Durante la misma época, en paralelo al proceso de asociacionismo docente y muy relacionado con él, se produjo un florecimiento de la prensa profesional. En 1867 aparecía El Magisterio Español que llevaba como subtítulo Periódico de instrucción pública. Órgano General de los establecimientos de enseñanza. Defensor de los intereses y derechos de los catedráticos y maestro. En años posteriores irán apareciendo un buen número de publicaciones periódicas profesionales del magisterio, tal y como ha estudiado en sus trabajos Antonio Checa Godoy (2002).

Tanto las asociaciones de maestros como las publicaciones profesionales contribuyeron a conformar la identidad profesional del magisterio. Estas plataformas, unidas a constantes reuniones y encuentros entre maestros, sirvieron para construir una cultura específica de la profesión. En esencia, coadyuvaron a erigir y divulgar un discurso, más o menos compartido, integrado por reglas, normas, valores y discursos reivindicativos de las condiciones profesionales, que les daba especificidad y servía para reforzar su presencia y capacidad de influencia social (Comas; Sureda, 2014). La prensa profesional de los docentes se convertía así en un instrumento a través del cual manifestar sus reivindicaciones profesionales; en un sistema para divulgar sus críticas por los bajos salarios recibidos y el atraso en el cobro de los sueldos, pero también sobre las deficiencias de los edificios escolares o la escasez de recursos y materiales didácticos. Asimismo, la prensa pedagógica del magisterio servía para reforzar la identidad profesional y prestigiar la profesión frente a la sociedad, utilizando para ello artículos a través de los cuales los maestros manifestaban sus ideas, experiencias u opiniones, patentizando así su formación y preparación.

En algunos de estos artículos, los autores revelaban su posición frente a las nuevas ideas educativas, bien fuese para divulgarlas y darles apoyo bien para criticarlas. En algunos casos, especialmente cuando empezaron a difundirse las ideas de la Escuela Nueva a principios de siglo 20, algunos de estos textos servían para reivindicar la superioridad de los sistemas aplicados por los maestros españoles frente a los extranjeros o el carácter poco innovador de los considerados nuevos métodos por ser sus principios y técnicas ya habituales en la práctica de maestros locales. 
A su vez, esta prensa de la que venimos hablando estaba relacionada con otras plataformas que también servían para reforzar la cohesión profesional de los maestros y, al mismo tiempo, para fundamentar el prestigio social de su misión. Una de ellas fue la publicación de obras escolares. Hemos de recordar que fueron maestros y profesores los que hasta bien entrado el siglo 20 controlaron buena parte de la publicación, edición y distribución de libros de texto, una actividad que les reportaba importantes ingresos y reconocimiento social. La relación de los docentes con el mundo editorial fue muy estrecha e incluso encontramos a profesionales de la enseñanza en el origen de algunas importantes editoriales especializadas en obras escolares. Es el caso, por ejemplo, de los orígenes de la prestigiosa librería Hernando de Madrid, estudiada por J. F. Botrell (1989), creada en el año 1828 por el maestro Victoriano Hernando y Palacios y especializada en obras didácticas y escolares. También tuvo orígenes relacionados con la actividad docente la editorial Paluzie de Barcelona, creada por el maestro Esteban Paluzíe y Cantalozzella (1806-1873). Maestro era también el gerundense Josep Dalmau Carles (1857-1928), otro de los creadores de una potente empresa editora de libros escolares y obras educativas como fue la editorial Dalmau, Carles \& Cia., fundada en 1904 y mantenida como empresa independiente hasta 1981. Por mencionar otro ejemplo significativo podemos hacer referencia a Miquel Porcel y Riera, que siendo regente de la escuela de prácticas anexa a la Normal de Palma publicó numerosas obras escolares, que vendió por toda España y países americanos, en las que aplicaba la graduación escolar ${ }^{2}$.

La relación entre la construcción de la identidad profesional de los docentes y el mundo editorial se puede observar también, además de su presencia en las revistas estrictamente profesionales, en su participación como autores, directores o editores en otras muchas revistas de todo tipo y especialmente en las relacionadas con la temática educativa o instructiva, como se demuestra en la obra de Checa Godoy ya citada.

Dado el contexto descrito hasta aquí, el objetivo fundamental de este trabajo es, por un lado, estudiar la concepción que de la educación tenía Rufino Carpena a través del análisis de sus artículos; y, por otro, analizar la revista Educacionista, una publicación escolar editada durante los años 1912 y 1913 en Llucmajor, Mallorca, por este maestro. Contenidos escrito y visual -hemos de apuntar ya aquí que la fotografía abunda y desempeña un rol significativo dentro de la revista- se entrelazan y nos van dando muestra, a medida que avanzamos en el estudio de los diversos números editados, de algunas de las cuestiones apuntadas hasta el momento, como por ejemplo de cómo se utiliza una publicación escolar para reivindicar la importancia de la profesión docente

El presente artículo se estructura a partir de un primer apartado en el que se señalan algunos aspectos básicos relativos a la situación escolar de Baleares, concretamente Mallorca, durante las primeras décadas del siglo 20. En segundo lugar, el lector encontrará una serie de apuntes relativos a la trayectoria profesional de Rufino Carpena Montesinos. Seguidamente, se presentan una serie de argumentos relativos al discurso pedagógico y la concepción de la profesión docente que se extraen de la lectura y análisis

\footnotetext{
${ }^{2}$ Sobre la relación entre profesionales de la enseñanza y la edición de libros escolares puede consultarse Sureda (1997). Específicamente sobre M. Porcel i Riera puede consultarse Payeras (2008). 
de algunos de los artículos publicados por el maestro en diferentes revistas de la época. En último lugar, se plasman las cuestiones esenciales que se traducen del estudio del contenido escrito y visual de la revista Educacionista.

\section{La escuela en Mallorca en las primeras décadas del siglo 20}

Al inicio del siglo 20, el sistema educativo en Baleares resultaba verdaderamente deficitario y presentaba graves carencias, de forma similar a lo que sucedía en el conjunto del Estado español. La oferta educativa pública era muy deficiente y la falta de plazas escolares no era tampoco suficientemente cubierta por una oferta privada generalmente religiosa. Aunque a finales del siglo 19 entre los sectores del profesorado más innovado se comenzase ya a defender la necesidad de graduar la enseñanza (Viñao, 1990), las escuelas seguían siendo unitarias y hasta 1912 no se inauguraría en la ciudad de Palma, la capital de Mallorca, la primera escuela graduada. En las escuelas unitarias a las que acudían por separado niños y niñas los métodos eran muy tradicionales: aprendizaje memorístico, rígida disciplina y escasa atención a actividades prácticas, experimentación o a la cultura y realidad que rodeaban la escuela. Los maestros, aislados en sus escuelas, tenían pocas posibilidades de mejorar su formación y de intercambiar experiencias con sus compañeros. Para hacer frente a las deficiencias del sistema escolar, a lo largo de las últimas décadas del siglo 19 y primeras del 20, fueron apareciendo en Baleares diversas iniciativas innovadoras.

A pesar de este panorama general, desde mediados del siglo 19 el magisterio público comenzó a mostrar en Baleares capacidad organizativa y voluntad de influir socialmente para defender sus intereses y reivindicar el prestigio de la profesión. En 1872 se constituyó la Asociación de Maestros de Baleares y a principios del año siguiente ésta comenzó a publicar su órgano de expresión, la revista El Magisterio Balear. Esta publicación mostrará un talante liberal, moderado y abierto a las nuevas ideas educativas y se convertirá en una de las revistas profesionales del magisterio que más duración tendrá en España. A excepción de algunos intervalos en que no se publicó, siguió apareciendo de forma regular hasta finales de la guerra el 1939.

El Magisterio Balear contribuyó a mejorar la formación de los maestros, aunque la difusión de las propuestas más renovadoras impulsadas por la Institución Libre de Enseñanza - ILE -, que había dado lugar a la creación de dos centros escolares, uno en el pueblo de Pollença en 1879 y otro en Palma al año siguiente, tan solo alcanzaron a un reducido grupo de maestros (Colom; Díaz, 1977; Salas, 1999). La renovación educativa de Baleares experimentó un importante impulso a partir de 1915 gracias a las iniciativas del inspector Juan Capó, quien creará en el año 1918 un centro de formación e investigación al que llamará, por influencia de la ILE, Museo Pedagógico Provincial (Colom, 1993). 


\section{Rufino Carpena Montesinos: trayectoria profesional}

Rufino Carpena Montesino ${ }^{3}$, editor de Educacionista, fue un personaje singular (Garcerán, 2005; 1999). Un prototipo de profesional del magisterio celoso de su profesión. Dispuesto en todo momento a defender sus derechos y a reclamar mejoras para la educación. Lo que hoy en día llamaríamos un sindicalista. Fue también un reformador social que propuso e impulsó acciones de mejora social y de tipo cultural desde posiciones regeneracionistas de orientación conservadora. Consideraba que la actuación de la escuela debía superar las paredes del aula para conseguir así influir en la sociedad a la que pertenecía. Su presencia en la prensa, en revistas, foros diversos y en el movimiento asociativo del magisterio fue muy activa durante toda su vida profesional e incluso después de su jubilación. Publicó también diversas obras de tipo didáctico y artículos sobre temas relacionados con la enseñanza o exponiendo sus proyectos de reforma social.

Carpena nació en la murciana población de Yecla en el año 1860. Desde 1882 se dedicó al magisterio, primero en un colegio privado para acceder posteriormente (1886) al magisterio público. En 1886 lo encontramos en una escuela unitaria de Balaguer, provincia de Lleida. En 1887 es maestro de la escuela nacional de Gurb en la comarca de Osona. En el año 1890 figura en la escuela de Vila-rodona, provincia de Tarragona, lugar desde el que va a proponer la creación de una Asociación de todos los maestros de España para defender sus interese ${ }^{4}$. Ese mismo año, desde el Boletín de primera enseñanza de la provincia de Gerona, reclama que se haga efectiva, y obligatoria para todos, la educación y la instrucción general ${ }^{5}$. Y es que en esa fecha El Magisterio Balear ya le califica de "Entusiasta propagandista a favor de los intereses del Magisterio"6. Aún en Tarragona, publica el texto Método de lectura y escritura simultáneas (1892). Este mismo año asiste al Congreso Pedagógico Hispano-Portugués-Americano, alineándose con los que se oponían a las propuestas favorables a la igualdad de los hombres y las mujeres $^{7}$. En 1896 publica la obra Nomenclátor Escolar que recoge exhaustivamente la situación escolar de 9387 ayuntamientos de España con un prólogo de Rufino Blanco. La publicación fue declarada de texto para las Escuelas Normales.

En el año 1896, Rufino Carpena fue destinado como maestro nacional a la escuela de la población de Muro, en la isla de Mallorca, donde el año anterior había tomado posesión como maestra de la escuela de niñas su hermana Margarita Carpena. En esta localidad Carpena desarrolla ya una importante labor de dinamización cultural creando la asociación benéfica Lectores Murenses cuyos estatutos redactados por Carpena se publicaron en 1902. Como en los estatutos se define, los objetivos y finalidades de la asociación eran desarrollar el gusto de los jóvenes hacia las buenas lecturas dando a

\footnotetext{
${ }^{3}$ En el Archivo General de la Administración de Alcalá de Henares puede consultarse el expediente personal de Carpena. Encontramos datos sobre su vida profesional, noticias sobre las múltiples actividades que realizó a lo largo de su vida y de sus opiniones plasmadas en artículos y cartas en múltiples revistas y diarios como El Magisterio Gerundense, El Magisterio Balear, La Escuela Moderna, El Magisterio Español, Gaceta de Instrucción Pública y Bellas Artes, La Vanguardia y muchos otros.

${ }^{4}$ El Magisterio Balear: periódico de primera enseñanza. Año XVII, n. 4, 25 ene. 1890, p. 4-5.

${ }^{5}$ Boletín de primera enseñanza de la provincia de Gerona Año XVI, n. 12, 25 mar. 1890.

${ }^{6}$ El Magisterio Balear: periódico de primera enseñanza. Año XVII, n. 9, 1 mar. 1890, p. 8.

${ }^{7}$ Véase la carta con su firma, entre otras, publicada en La Unión Católica, 5 nov. 1892, p. 2. En ella se afirma la oposición de los firmantes a "una absurda y anticristiana emancipación de la mujer". 
conocer las ventajas que obtiene el hombre a ellas aficionado; difundir la instrucción por medio de la lectura racional de libros y periódicos; o fomentar la educación social y cívica por medio de ejemplos y amenas conferencias mensuales o trimestrales.

Durante su estancia en Muro Carpena tuvo un litigio con el ayuntamiento de la localidad reclamando el pago de la vivienda para él y su hermana ${ }^{8}$. Esta actuación es un ejemplo más del compromiso que mantuvo a lo largo de toda su vida por la dignificación de la profesión docente y la mejora de los derechos de los maestros (Llinares, 1985; 1986). Durante estos años publica varias obras para facilitar la enseñanza de las medidas legales, tabla de multiplicar, estudio de la gramática, conjugación y análisis, unos cuadernos de aritmética práctica y unos Ensayos de lecciones combinadas para los alumnos de primer grado con todas las nociones de enseñanza que abarcaba el programa oficial.

El 1903, abandonando la plaza de maestro de la escuela pública de Muro, viaja a la Argentina donde dirige el Colegio Hispano-Argentino de Bahía Blanca en la república argentina. Poco se conoce de aquel periodo. Más tarde, en Educacionista, Carpena incluirá una fotografía de un grupo de niños con un pie en el que se lee:

Nuestro Director, D. Rufino Carpena Montesinos, sin subvención de entidad alguna española, durante varios años ha experimentado en el extranjero la organización de una enseñanza verdaderamente graduada, de ocho grados. Uno de estos representa el grabado que antecede. Los niños aparecen retratados delante de un auxiliar y del Director, Sr. Carpena, en uno de los cuatro corredores del gran edificio, donde se distinguen perfectamente espléndidos patios circuidos de salas de clases, donde se observan plantas, pájaros, aire, luz, ventilación, alegría, salud y vida. Estas son escuelas atrayentes, educativas, centros de enseñanza como quisiera ver EDUCACIONISTA profusamente esparcidas por todos los pueblos de España. (Educacionista, n. 8, 10 nov. 1912, p. 5)

Recordemos que está hablando de una experiencia que transcurrió entre 1903 y 1909 y que la primera escuela graduada de España, la de Cartagena, empezó a funcionar en el año 1903, mientras que en Mallorca, y a pesar de que diversos maestros la venían reclamando desde los últimos años del siglo 19, no se inauguró el edificio de la primera graduada, la de Palma, hasta 1912.

Al abandonar la plaza de maestro para viajar a la Argentina, transcurridos unos años, Carpena tuvo que pedir su rehabilitación para reincorporarse a la escuela en España, trámite que ya inició en el año 1906 sin conseguirlo hasta 1908, con una sanción de seis meses. Finalmente, en enero de 1909 se le concede la reincorporación a la escuela nacional de Llucmajor. En esta localidad mallorquina va a desarrollar una importante labor educativa aplicando métodos modernos en la escuela, organizando excursiones con sus alumnos y actividades prácticas, dando importancia a los trabajos manuales y organizando exposiciones escolares. Al mismo tiempo imparte conferencias tanto en Llucmajor como en Palma, colabora con la Asociación de Maestros de Baleares, publica artículos en El Magisterio Balear y en la prensa local de Llucmajor. El 1911 es premiado en el III Concurso Nacional convocado por el Consejo Superior de Protección de la Infancia reconociendo su tarea educativa y social a favor de los niños así como su

\footnotetext{
${ }^{8}$ Sobre el litigio véase La Unión Republicana, año V, n. 1297, 2 oct. 1900, p. 3 
labor en la difusión de ideas en defensa de la mejora de la condición infantil. Entre las actuaciones que se reconocen con el premio se incluye la creación en 1911 de la Mutualidad Escolar de Llucmajor, una sociedad infantil con la finalidad de fomentar el ahorro entre los escolares (Educacionista, n. 2, 25 de julio de 1912, p. 8). Durante su estancia en Llucmajor, el maestro sigue impartiendo conferencias sobre temas educativos en distintos foros de las que dan cuenta la prensa de la época y las revistas profesionales. Es en esta localidad donde publica, entre los meses de julio de 1912 a julio de 1913, la revista ilustrada que es objeto de estudio en este trabajo: Educacionista. A mediados de diciembre de 1914 imparte en el Ateneo de Madrid una conferencia con el tema "La educación nacional. Manera de llegar a conseguir que este problema sea sentido en España por todas las clases sociales" de la que se informa en la Gaceta de Instrucción Pública y Bellas Artes, aspecto que da muestra de la popularidad alcanzada por Carpena (Gaceta de Instrucción Pública y Bellas Artes, 9 dic. 1914, p. 12).

La implicación en labores sociales por parte de Carpena no cesa, enviando en el año 1916, desde Llucmajor, una carta al presidente del Consejo de Ministros, que sería publicada en La Escuela Moderna, en la que se solicita la subvención de un desplazamiento a Madrid para presentar un proyecto que tenía por finalidad la construcción de casas y el ofrecimiento de alimentos baratos a las clases populares ( $\mathrm{La}$ Escuela Moderna, $1^{\circ}$ jan. 1916, p. 67).

En 1916 a Carpena se le asigna una escuela del barrio palmesano de S'Indioteria, Mallorca, donde su hermana también ocupará la plaza de la escuela de niñas. Parece que el maestro retrasó su incorporación y viajó a Madrid para presentarse a una plaza de inspector. El 5 de noviembre de 1916 el periódico madrileño conservador La Acción da cuenta de una asamblea de maestros convocada en la escuela Normal de la capital para reclamar mejoras profesionales. Además del director de la Escuela Normal la presidencia estaba ocupada per Rufino Carpena, a quien el periódico define como "incansable adalid de la postergada clase de maestros, que tiene acreditados sus entusiasmos con briosas campañas, de grata memoria para los mentores de la niñez" (La Acción, 5 nov. 1916, p. 5). El 4 de diciembre el diario madrileño El País da cuenta de una conferencia que aquel día debía pronunciar Carpena en el Ateneo con el título de "Nuevo concepto de Escuela Nacional y sus consecuencias en España" (El País, 4 dec. 1916, p. 3). Finalmente, al no obtener la plaza de inspector, se reincorpora a la escuela de S'Indioteria de Palma. La revista Baleares del 20 de agosto de 1919 publica una fotografía del maestro con algunos de sus alumnos, indicando en el pie de foto que Carpena había realizado varias excursiones instructivas con ellos (Baleares, 20 ago. 1919, n. 93, p. 21).

El 1919 es nombrado director de la escuela graduada de Piera en Barcelona. En la capital catalana ocupará la dirección de diversas escuelas graduadas hasta el momento de su jubilación en 1930 y participará como delegado provincial en la Confederación de Maestros. Hasta sus últimos años en la profesión, el maestro se muestra incansable, como lo califican sus mismos compañeros, defensor de los profesionales del magisterio. Su jubilación no augura unas condiciones económicas muy favorables y, por este motivo, algunos de sus compañeros de profesión de toda España proponen hacer una colecta para que pueda comprar una casa (El Magisterio Español, n. 8.473, 31 oct. 1929, p. 300). En esta última etapa de su vida sigue haciendo propuestas de reformismo social para luchar contra la pobreza mediante la creación de nuevos pueblos con servicios y 
subsistencias a precios económicos y proyectos para crear cocinas colectivas para abaratar costes, un proyecto que denominó El puchero nacional ${ }^{9}$. Jubilado sigue defendiendo sus principios y a sus compañeros de profesión, mandando cartas al gobierno y a los ministros. En 1930 se presenta como candidato independiente a Cortes por Barcelona con un programa basado en sus ideas educativas y sus proyectos de reformismo social ${ }^{10}$.

\section{El discurso pedagógico de Rufino Carpena a través de sus artículos}

Las ideas pedagógicas que expone Rufino Carpena en sus artículos van dirigidas fundamentalmente a reforzar el discurso de dignificación de la profesión de maestro. Conocía las teorías educativas más novedosas de su época, de hecho aplicaba sistemas y prácticas educativas muy innovadoras, pero no se dejaba seducir por las novedades ni se declaraba seguidor de ninguna tendencia concreta. No encontramos en sus artículos principios teóricos sino ejemplos y reflexiones sobre la práctica profesional. En sus escritos localizamos referencias a autores del pensamiento pedagógico español del siglo 19 y entre ellos valora los que consideraba que tenían más experiencia práctica y conocían mejor las escuelas, como Andrés Manjón, Julian López Catalán, Eugenio Bartolomé Mingo, Pedro de Alcántara García Navarro, Pilar Pascual de San Juan, Baltasar Perales o Ignacio Ramon Miró, todos ellos maestros que habían publicado sus experiencias. Mostraba respeto por el creador de las escuelas normales, Pablo Montesino, o por pedagogos de prestigio como Pestalozzi y Fröebel. Considera que el ejercicio profesional y la experiencia profesional deben ser las fuentes fundamentales de las ideas pedagógicas ${ }^{11}$.

En los artículos de Rufino Carpena encontramos fundamentalmente reflexiones sobre la práctica diaria, más que alusiones a las grandes teorías. La importancia que concede al intercambio de experiencias prácticas entre maestros para la mejora de la educación la podemos encontrar, por ejemplo, en un artículo suyo publicado en La Escuela Moderna en el año 1892. En este texto se aborda el tema de las Conferencias Pedagógicas -sesiones formativas para los maestros que habían sido creadas por Ley de 16 de julio de 1887 para mejorar la formación de los maestros-. Su misión era la de favorecer el intercambio de experiencias entre los maestros y el debate sobre la práctica, pero en realidad se convirtieron en un ejercicio muy academicista y con poca participación de los maestros (Ávila; Holgado, 2014). En su artículo, Carpena se hace eco de este sesgo poco práctico y que dificulta el intercambio de experiencias y propone que en lugar de actos públicos que obligan a una cierta "importancia académica" ( $p$. 114) y lucimiento formal de los que intervienen a costa del auténtico intercambio de experiencias y de

\footnotetext{
${ }^{9}$ Son ideas que ya venía exponiendo anteriormente y que presenta en su obra Vida hermosa en poblados modernos Sistema Carpena: novela semi-històrica que encierra un proyecto de aplicación y beneficio mundial.

${ }^{10}$ El semanario Mirador de Barcelona del 9 de abril de 1937 informa de que Rufino Carpena se presenta a las elecciones a Cortes por Barcelona creando su propio partido y habiendo publicado el primer número de una revista titulada La Nueva Política en la que se presenta su programa político.

${ }^{11}$ En un artículo suyo en El Magisterio Balear publicado en 1901, después de exponer su sistema de corrección de los textos escritos indicando a sus alumnos donde están los errores para que sean ellos los que busquen la forma correcta de escribir la palabra, afirma: "Este procedimiento no lo aprendimos en la Normal sino que, cual otros muchos, nos lo ha ido sugiriendo la práctica, la práctica en la enseñanza, en la que discurrimos cada día al objeto de allanar dificultades a los niños y vencer obstáculos que frecuentemente se oponen a las teorías e ideales pedagógicos" (Carpena, 1901, p. 142).
} 
información entre maestros se hagan reuniones más "frecuentes, íntimas y familiares" ( $p$. 114 ) en las mismas escuelas sin tantas pretensiones, pero más eficaces. Critica que estas sesiones se hagan más para quedar bien ante la opinión pública que para mejorar la formación de los maestros y afirma que

para evitar una ridiculez o fracaso ante dicha opinión que asiste o puede asistir a las Conferencias de hoy se esfuercen los maestros ponentes en dar a sus disertaciones o discursos un tinte o barniz de oratoria, cosa que si bien puede atraer la atención de unos pocos curiosos y periodistas en cambio fastidia y cansa a muchos comprofesores porque éstos poco nuevo oyen, pues están hartos de leer teorías pedagógicas, y pueden estudiar cuantos tratados de Pedagogía se publiquen, sin moverse de casa. $Y$ he aquí, según creemos, el principal motivo de la escasa asistencia de maestros a tales reuniones. (Carpena, 1892, p. 115)

En 1900 encontramos otro de sus numerosos artículos que nos puede ayudar a conocer su pensamiento. Publicado en El Magisterio Balear trata el tema de los libros escolares. Como es sabido, el rechazo a la utilización de libros de texto es uno de los principios programáticos de los pedagogos de la ILE, la corriente más innovadora de la enseñanza en España en las últimas décadas del siglo 19 y primer tercio del 20, hasta la Guerra Civil. En el artículo al que hacemos referencia, después de reconocer la importante labor que han realizado muchos maestros, en condiciones difíciles y con poco reconocimiento social, para dotar a la escuela de buenos libros escolares se manifiesta partidario de un uso moderado de los mismos. También aquí, como en otros casos, fundamenta sus opiniones en su experiencia. Concretamente hace alusión a lo que pudo conocer en su experiencia en un colegio antes de acceder a la enseñanza pública. En el texto, Carpena manifiesta que en aquel colegio primero tuvo un director que era contrario a los libros escolares y después otro que todo lo basaba en ellos. De esta forma pudo comprobar las ventajas e inconvenientes de cada sistema o como él mismo afirma que

la experiencia me ha enseñado que si no debo ser partidario de la completa eliminación del estudio de memoria en las diferentes asignaturas escolares, tampoco he de serlo de que se sobrecargue a los niños de libros y más libros; porque si lo primero es vicioso por defecto, lo segundo es perjudicial por excesos. Las consecuencias de ambos extremos las he presenciado y puedo hablar con algún conocimiento de causa. (Carpena, 1900, p. 12)

Carpena se manifiesta contrario a los aprendizajes memorísticos y defiende siempre una enseñanza de fundamentación intuitiva cimentada sobre la propia realidad, en la que prime el juicio más que la memorización. Carpena combina en sus artículos la defensa de una reflexión sobre la práctica educativa con la fijación de principios educativos que garanticen un aprendizaje efectivo por parte de los alumnos. En un artículo publicado en enero de 1901 en El Magisterio Balear expone, también a partir de una experiencia con sus alumnos, cómo es necesario comprobar lo que realmente entienden los niños cuando se les explican las máximas morales y cómo el maestro debe adaptar a la inteligencia infantil las explicaciones que hace a partir de la comprobación de cómo son entendidas y asimiladas por los niños (Carpena, 1901, p. 41). 
Un buen resumen de las ideas educativas de R. Carpena, con una fuerte inspiración en el intuicionismo, lo encontramos en la crónica de una de sus múltiples conferencias, publicada en El Magisterio Balear en 1912. Allí habla de la necesidad de seguir un procedimiento instructivo que discurra desde lo más simple, cercano y conocido hacia los conceptos más complejos; las ideas antes que las palabras; los hechos vividos y recientes antes que las añejas historias. Así sigue el texto al que hacemos referencia:

Los naturales paisajes primero que los lienzos o láminas, la visión o audición antes que la descripción; la descripción verbal antes que la escrita; la enseñanza de la escritura sin reglas antes que la de preceptos; los trazados de las letras a la vez que su conocimiento y alternando con la lectura; la escritura libre de ideas y pensamientos, antes que la lectura de palabras y oraciones gramaticales, como si dijéramos el lenguaje escrito y verbal antes que la gramática; el cálculo mental a la presencia de números formados por cosas positivas antes que la aritmética, el trazado de líneas antes que la geometría; ligerísimos croquis antes que el dibujo y antes que los mapas; los mapas mudos de distintos colores, antes que la geografía; las observaciones de fenómenos naturales, así como las cualidades de los seres, vistas tocadas (experimentadas en lo posible) antes que las ciencias físico naturales; la reflexión e interrogaciones sobre actos de bondad o maldad acaecidos diariamente entre los niños, antes que los deberes abstractos de Moral y Religión; el ejercicio de los buenos modales o gimnasia antes que el precepto sobre urbanidad y robustez; el ejercicio y manejo del fusil, antes que los preceptos de disciplina y código militar; a la enseñanza de un derecho inmediatamente la de su deber y viceversa; jugar, cavar, desterronar y regar un trozo de tierra antes que las definiciones agrícolas, etc., etc. (Carpena, 1912, p. 117)

Un ejemplo de cómo Rufino Carpena articula un discurso pedagógico fundamentado en la reivindicación del ejercicio del magisterio y en la experiencia profesional lo encontramos en otro de sus artículos, en este caso dedicado al método Montessori. El escrito ya tiene un título bien significativo: Defendiendo el magisterio español y como subtítulo Carta abierta sobre las escuelas Montessori ${ }^{12}$. La carta va dirigida al psiquiatra mallorquín Juan Alzina Melis, profesional dedicado a la psicopedagogía y principal impulsor del Instituto para niños deficientes del Ayuntamiento de Barcelona, creado en 1917, quien había escrito un artículo dando a conocer el método de María Montessori ${ }^{13}$. Por aquellos años, el método de la pedagoga italiana tenía gran predicamento entre los círculos renovadores de la educación catalana e influencias en Baleares. Carpena, quien se define como un práctico de la enseñanza y se declara seguidor y respetuoso con las aportaciones montessorianas, aprovecha para hacer una reivindicación de la labor de los maestros españoles que, con muchas dificultades y poco reconocimiento social, consiguen grandes resultados. Carpena acaba el artículo afirmando:

Por último, Sr. Alsina, para terminar le diré: si $V$ pudiera lograr que en España se nos proporcionaran medios adecuados, locales, el personal necesario y ese calor que ahora se está dando en Barcelona a tan simpática Doctora italiana, a los pocos días que con tales alijos trabajáramos, invitado quedaría V. Y "todos" los que como V. piensan a

${ }^{12}$ El Magisterio Balear: periódico de primera enseñanza, año XLIV, n. 8, 19 feb. 1916, p. 71-72; y año XLIV, n. 9, 26 feb. 1916, p. 85-87.

${ }^{13}$ Sobre la difusión del método Montessori en Catalunya véase Comas; Sureda (2012). Hist. Educ. (Online) 
visitar nuestras escuelas. Creo que se persuadirían pronto. Tal vez V. dijera también con nosotros de que nada habríamos de envidiar aquí en sistemas y procedimientos educativos. Vdes. verían como las novedades pedagógicas importadas del extranjero llamadas Montessori también podrían llamarse Carpena, Marcarmón, etc. ${ }^{14}$

Tal y como hemos visto a lo largo de estas páginas, el discurso pedagógico de este profesional queda patente y se traduce a la perfección a través de la lectura de sus artículos y publicaciones. Además, Rufino Carpena construye un modelo de pedagogía escolar, un concepto que él utiliza en sus escritos con cierta frecuencia y que se fundamenta sobre la experiencia profesional, la innovación a partir de la práctica y el intercambio de experiencias entre maestros. Un cuerpo doctrinal que a la postre dignifica la profesión y da cohesión e identidad al colectivo docente.

\section{Educacionista}

En 1912 Rufino Carpena pone en marcha la andadura de la revista Educacionista, una publicación que sirve, por un lado, como plataforma para dar visibilidad a la actividad escolar y, por otro, como instrumento para difundir las ideas de su director.

Desde el primer número que se edita el 25 de julio de 1912 y hasta febrero de 1913 la publicación tendrá una periodicidad quincenal, saliendo los días 10 y 25 de cada mes, para pasar posteriormente a una edición mensual, publicándose el día 10 de cada mes ${ }^{15}$. El coste inicial de la revista es de 15 céntimos el ejemplar, con posibilidad de realizar una suscripción trimestral por 1 peseta o anual por 4 pesetas. A partir del número 2 no se venderán ejemplares sueltos, ofreciéndose únicamente la posibilidad de suscripción por periodos más amplios. A partir del número 13 el coste de suscripción trimestral se ve incrementado a 2 pesetas, tarifa que se mantendrá hasta su último número. Las dificultades económicas para llevar a cabo la empresa de creación y mantenimiento de una publicación de este tipo en la época no eran sencillas. Por este motivo, Carpena mandaba ejemplares de la revista de forma gratuita a personalidades y colegas y solicitaba subscripciones y aportaciones ${ }^{16}$.

La publicidad será otro de los medios mediante los cuales su director consiga recursos de financiación. En los primeros ejemplares no aparecerán anuncios, pero pronto veremos insertos en las últimas páginas diversos cuadros de publicidad. Asimismo, Carpena aprovechará la publicación para difundir sus obras, utilizando para ello, sólo en

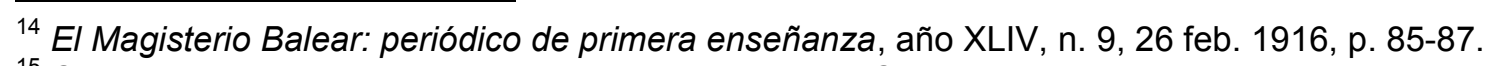

${ }^{15}$ Coincidiendo con el paso de quincenal a mensual, Carpena reconocía en El Magisterio balear que, en medio año, había perdido 1500 pesetas (El magisterio balear: periódico de primera enseñanza, año XLI, n. 5,8 feb. 1913, p. 35).

${ }^{16}$ El directo de Educacionista anuncia ya en el primer número que el pago debe efectuarse por anticipado. Aún así, señala que "son pocos los que así lo han hecho", motivo por el cual, en lo sucesivo, "este será el único número de Educacionista que remitiremos a los que todavía no tienen la suscripción abonada" (Educacionista, n. 1, 10 oct. 1912, p. 3).

Hist. Educ. (Online) Porto Alegre

v. 21

ก. 51

Jan./abr., 2017

p. $229-251$ 
algunos ejemplares, su última página. Así, por ejemplo, vemos en el número 9 un listado, con una breve reseña ${ }^{17}$, de sus principales obras: Método de lectura y escritura simultáneas, Nomenclátor escolar, Cuadro de medidas legales en España, Cuaderno para aprender la tabla de multiplicar, Preparación práctica al estudio de la Gramática, Cuartillas de conjugación y de análisis, Conferencia pedagógica, Ensayos de lecciones combinadas.

En total se publican 18 números en los que encontramos una serie de secciones habituales. Dos de ellas aparecen prácticamente en todos los números: la Sección de niños y la Sección de hombres. La sección de niños incluye pequeñas composiciones de los alumnos o muestras de sus trabajos escolares como mapas o dibujos. En todos los casos estas colaboraciones van firmadas y se hace constar la edad del escolar. En algunos casos, los textos de los niños se presentan reproduciendo el manuscrito, aspecto que permite observar la caligrafía que se utilizaba. Los textos infantiles que reproduce Educacionista tienen contenidos muy diversos. Algunos son cartas de los hijos a los padres o de los alumnos al maestro. Por ejemplo, en uno de los números el joven Juan Rubí de 8 años escribe a su padre que se encuentra en Buenos Aires para saber "cómo se encuentra y cuando piensa regresar" (Educacionista, n. 2, 25, jul. 1912, p. 5).

En otro caso es Miguel Pons, joven de 11 años, que escribe al maestro para decirle que no puede acudir a clase por tener que ir cada día a curarse una pierna y después ayuda a su padre a escribir los índices de nacimientos en uno de los registros del juzgado (Educacionista, n. 2, 25 jul. 1912, p. 5). En otras ocasiones estas composiciones infantiles describen actividades de la escuela o visitas y excursiones. Por ejemplo, Bartolomé Durán, de 11 años de edad, describe un paseo por las afueras del pueblo, acompañados por un sargento y un capitán, en el que hicieron una demostración de instrucción militar y terminaron el día jugando y merendando (Educacionista, n. 4, 10 sep. 1912, p. 7). Otras pequeñas composiciones hacen referencia a lo que se hizo durante las vacaciones o el primer día de clase. No sólo participan de la revista los alumnos del propio Carpena sino que también encontramos las colaboraciones de las alumnas que tiene en la población de Muro la hermana del director, la maestra Margarita Carpena. Asimismo, en otros casos se incluyen cartas mandadas por alumnos de otras escuelas, a los que llegaba la publicación Educacionista, en las que se comenta el contenido de la revista o se aportan explicaciones sobre diversas actividades escolares ${ }^{18}$. La publicación de trabajos infantiles y el intercambio de cartas entre los alumnos de distintas escuelas ha sido el motivo por el cual algunos especialistas se han aventurado a considerar esta iniciativa como un antecedente de las técnicas de C. Freinet (Jaume i Campaner, 2010), cuestión que por otro lado habría que plantear con sumo cuidado pues no todos los especialistas en Freinet coinciden en esta afirmación.

\footnotetext{
17 Veamos cómo se reseña alguna de estas obras: Nomenclátor escolar: útil libro de consulta a los maestros, aprobado de texto para las escuelas normales, por R. O. de 11 de febrero de 1897. Consta de 350 páginas en cuarto mayor. Da noticias de los 9387 ayuntamientos de España, y contiene, entre otros, los datos siguientes: habitantes de cada pueblo, vías de comunicación, estado de los locales de las escuelas, afición a la enseñanza en el pueblo, cómo suelen pagarla en éste, importe de las retribuciones por escuela, estación de ferrocarril más próxima al pueblo, productos, clima, aguas, etc." (Educacionista, n. 9, 25 nov. 1912, p. 10).

${ }^{18}$ Véase por ejemplo la sección Intercambio escolar en Educacionista, n. 9, 25 nov. 1912, p. 8. Una nota titulada Intercambio escolar, publicada en el primer número de la revista, ya anima a los "niños de cualquier escuela nacional española, europea o americana” a colaborar con la revista. 
Dentro de esta sección de niños se incluyen también ejemplos de las actas del jurado infantil ${ }^{19}$ constituido por Rufino Carpena en la escuela con el fin de que un tribunal integrado por los propios infantes juzgase las actuaciones incorrectas de sus compañeros. Veamos uno de estos casos en el que, substituyendo los nombres por las letras $A$ y $B^{20}$, se recoge lo siguiente:

DECLARACIONES. El niño A acusó al niño $B$ por haber escrito éste una carta en nombre de A dirigida a una casa, diciendo cosas y palabras feas, siendo castigado A por su madre. El niño $B$ ha dicho que es verdad. SENTENCIA. Es condenado el niño $B$ con la pena de ir a pedir perdón a la misma casa, y si no va la condena será quedarse en la escuela media hora por la mañana y media por la tarde hasta haber vacaciones. (Educacionista, n. 14, 10 mar. 1913, p. 14)

Por otra parte, en el apartado denominado Sección de hombres ${ }^{21}$ se incluyen textos de muy distinta naturaleza y procedencia, en la mayoría de los casos relacionados con la educación. Repasando sus páginas encontramos, por ejemplo, muestras de apoyo a la publicación - breves cartas que Rufino Carpena fue recibiendo de diferentes profesionales en las que se le informa de la emisión de algún donativo para la revista, peticiones de suscripción o sencillas palabras de entusiasmo y apoyo por la iniciativa emprendida -; artículos recogidos de otras publicaciones; algunos textos de alumnos que cursan estudios en centros de enseñanza secundaria o en la Escuela de Bellas Artes; artículos de otros maestros.

Otra de las secciones fijas de la publicación es la de personajes públicos. En este apartado se presentan a políticos, empresarios, profesionales, escritores, etc. a partir de un breve texto en el que se ensalzan especialmente las actuaciones o manifestaciones que la persona a la que se dedica la sección haya tenido dando apoyo a la educación, la cultura o el progreso social. Esta sección siempre incluye una fotografía del personaje y un texto en el que, como decimos, se destacan las virtudes de la persona que se presenta.

Además de estas secciones, la revista Educacionista recoge también un modelo del tipo de proyectos y empresas educativas y sociales a las que Rufino Carpena dedicó grandes esfuerzos a lo largo de toda su vida. Su idea, básicamente, consistía en crear una gran ciudad educadora, en la que no existieran ni analfabetos ni malas costumbres, pero sobre todo un lugar en el que a nadie le faltara un techo sobre el que resguardarse y un plato de comida que poder llevarse a la boca. Así, por primera vez en el número 4 de la publicación, el director nos presenta lo que él denomina como el magno proyecto. La descripción que nos hace de su idea es la siguiente:

${ }^{19}$ La creación de Tribunales Infantiles en las escuelas, como el creado en Llucmajor, es uno de los proyectos que defendió R. Carpena y que ilustra muy claramente la mentalidad regeneracionista de aquel maestro. Sobre este tema mandó en 1915 un informe al Senado y al Ministerio de Gobernación que remitió el documento para su estudio a la Junta Superior de Protección de la Infancia. Véase El Magisterio Balear, año XLIII, n. 51, 11 dic. 1915, p. 399-400.

${ }^{20}$ En el acta constan los nombres de los que formaron el tribunal con un presidente, un vicepresidente, un secretario y dos vocales.

${ }^{21}$ En el número 4 de Educacionista, en una nota a pie de página relativa al título de esta sección se especifica: "En esta sección colaboraran también señoras: distinguidas profesoras normales, maestras, escritoras educacionistas, nacionales y americanas especialmente" (Educacionista, n. 4, 10 sep. 1912 , p. 2). 
Iniciar la fundación de un gran grupo escolar, denominado Santa Rosa de Lima, en sitio o paraje propio para que en torno suyo se pueda edificar un pueblo, una ciudad nueva [...] pueblo o ciudad moderna con aguas abundantes, perspectivas alegres, tranquilas y morigeradas costumbres, comodidades y risueños encantos de cariño. (Educacionista, n. 4, 10 sep. 1912, p. 2)

Una ciudad a la que califica como "un ejemplar de activas viviendas higiénicas" (p. 2) o "una síntesis del bienestar humano" (p. 2). Una ciudad nos dice, sin analfabetos, donde no falten iglesias, escuelas, teatros, gimnasios, paseos, etc. Un mes después, Carpena publicará (n. 6) un croquis y símil de modelo de uno de los pabellones interiores de clases, dando muestra así de su empeño en la consecución de este proyecto. Como en otras ocasiones a lo largo de su vida, R. Carpena comunicó este proyecto a distintas personalidades para conseguir su apoyo y así lo indica en el texto que incluye en Educacionista. Carpena continuará explicando su proyecto en números sucesivos.

Hasta aquí se ha presentado un breve resumen de los principales contenidos escritos que aparecen en esta publicación; pasemos ahora a analizar el contenido visual de la misma.

\section{El papel de las imágenes y fotografías en Educacionista}

Un aspecto a destacar de Educacionista es la abundante presencia de imágenes en sus páginas. Constituye pues una revista ilustrada en la que las fotografías adquieren un papel primordial, formando un conjunto comunicacional que se une al texto escrito. Es decir, en el seno de un soporte físico, la revista, interaccionan textos e imágenes, haciendo de la primera un material mucho más atractivo.

Dentro del amplio grupo de imágenes localizadas podría establecerse una primera división general en dos grandes grupos; un primero integrado por dibujos y mapas elaborados por los niños, a través de los cuales se daría muestra de algunos de los trabajos realizados dentro de la escuela y que formarían parte del denominado cuaderno escolar; y un segundo grupo compuesto por fotografías y fotograbados.

Dentro del primer grupo, por ejemplo, nos encontramos con un amplio conjunto de mapas que forman parte de una serie de ejercicios prácticos de geografía y agricultura realizados por los alumnos de la $1^{\text {a }}$ Escuela Nacional de niños de Llucmajor. En la revista se nos dice: "los croquis de mapitas, muchos de éstos, son trazados por los alumnos en sus casas, en cuartillas verdes ad-hoc, facilitadas por su maestro quien acostumbra a sus discípulos a mucho trazado a pulso" (Educacionista, n. 10-11-12, dic. 1912 y ene. 1913, p. 8). Los niños cuentan con total libertad para trazar sus mapas en colores diversos y, una vez corregidos, éstos se pasan a otras cuartillas en limpio. Rufino Carpena indica que, en el último curso, los niños de dicha escuela realizaron unos 12.000 ejercicios de este tipo, que serían mostrados a final de curso en una exposición abierta al público. Veamos un ejemplo de estos mapas en la siguiente imagen. 
Imagen 1 -

Diversos croquis-mapas de España realizados por alumnos en noviembre de 1912.

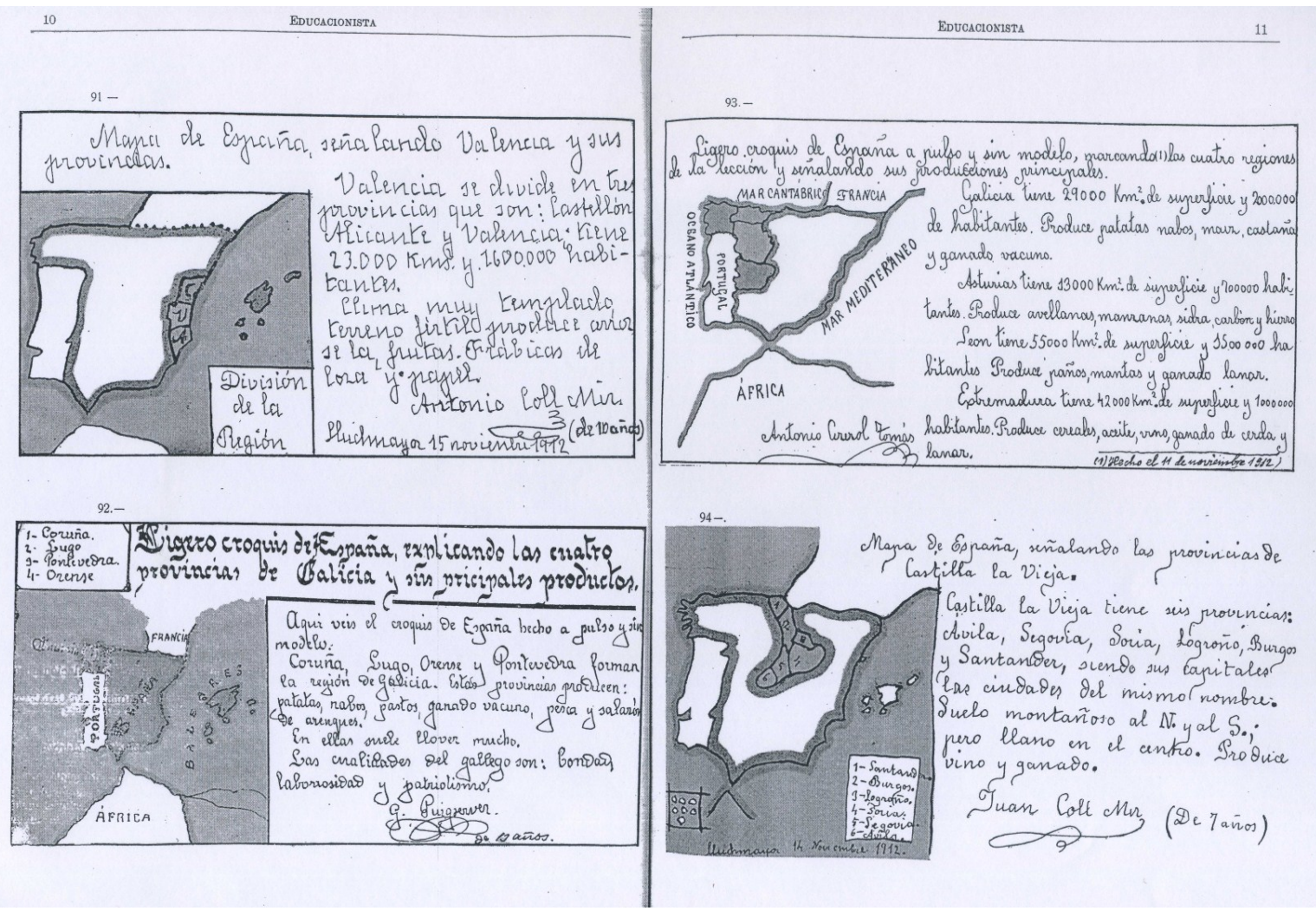

Fuente: Educacionista, n. 10-11-12, dic. 1912 y ene. 1913, p. 10 y 11.

El segundo grupo lo constituye una importante colección de fotografías. A lo largo de todos sus números, Educacionista publicó cerca de un centenar de ellas que pueden agruparse fácilmente en una serie de categorías que pasamos a detallar: retratos de personajes; retratos de estudiantes; fotografías de iniciativas sociales; de grupos escolares; excursiones y prácticas al aire libre; espacios escolares; exposiciones escolares; actos académicos; estudiantes desempeñando tareas; fotografías de monumentos y esculturas; grabados y fotograbados; y reproducción de postales y tarjetas de felicitación.

La presentación de personajes, acompañados siempre de su retrato, es una de las constantes en todos y cada uno de los números de la revista. De ahí que este tipo de fotografía represente más del $50 \%$ de las instantáneas publicadas. Claramente se observa un intento por reforzar el texto con el que se presenta al personaje a través de una fotografía que permite al espectador visualizarlo y "ponerle cara". De hecho, la idea de Carpena, tal y como se refleja en el primer número de la revista, era colocar en la entrada de la escuela una galería de retratos y biografías de aquéllos que se interesan "por la civilización y el progreso de nuestra Patria" (Educacionista, n. 1, jul. 1912, p. 2). En la primera página de ese primer número ya aparece un retrato del propio Carpena, con indumentaria elegante - traje, camisa y pajarita -, a la que acompaña un texto redactado por Antonio Oliver Sastre, de 17 años de edad, en el que le califica como "uno de esos hombres de gran valor moral y de benevolencia suma hacia los niños" (p. 2). Entre los numerosísimos retratos de personajes que nos encontramos en esta revista cabe señalar 
algunos nombres a modo de ejemplo: Jerónimo Estades, Antonio Maura, Alejandro Roselló, Juan Valenzuela, Valeriano Weyler Nicolau, Margarita Carpena, Juan Benejam Vives, Mariano de la Vega, Venancio Álvarez Rodríguez, Gaspar Gestido, Juan Pujol Colomar.

Una segunda categoría de fotografías está representada por aquellas en las que se reproducen distintas actividades escolares. Entre estas podemos hacer referencia a la que, ya en el número primero, muestra reunidos algunos miembros de la junta de la mutualidad escolar de Llucmajor, entre ellos el mismo Carpena, algún otro adulto y varios alumnos de la escuela: todos ellos aparecen sentados en una mesa repasando atentamente documentación. En otra aparecen los alumnos, que según reza el pié de foto, forman parte de la sección militar posando con sus fusiles de madera. En otra aparecen, en el exterior, con un posado bastante informal, el grupo de alumnos que colaboran con la publicación. En diversas fotografías aparecen los alumnos y maestros en diversas excursiones; ejemplo de ello es la instantánea publicada en el número 4 en la que se muestra al grupo de alumnos en una excursión al Oratorio de Gracia. El pie de foto reza lo siguiente:

Los niños, después de haber comido, en bullicioso remolino, al saber que un fotógrafo se acerca a los pórticos donde todavía están las mesas que han servido para comer un suculento arroz, tortilla, etc. asaltan las mesas y los asientos otra vez, colocándose en la posición libre y amontonada con que aparecen en el fotograbado. (Educacionista, n. 4, 10 sep. 2012, p. 5)

Muestra de una excursión es también la fotografía tomada en el Monte de Randa, Mallorca, en la que los niños aparecen dispuestos en diferentes alturas, colocados para la foto y guarecidos en una cueva: imagen 2 . 
Imagen 2 -

Guarecidos en una cueva del Monte de Randa.

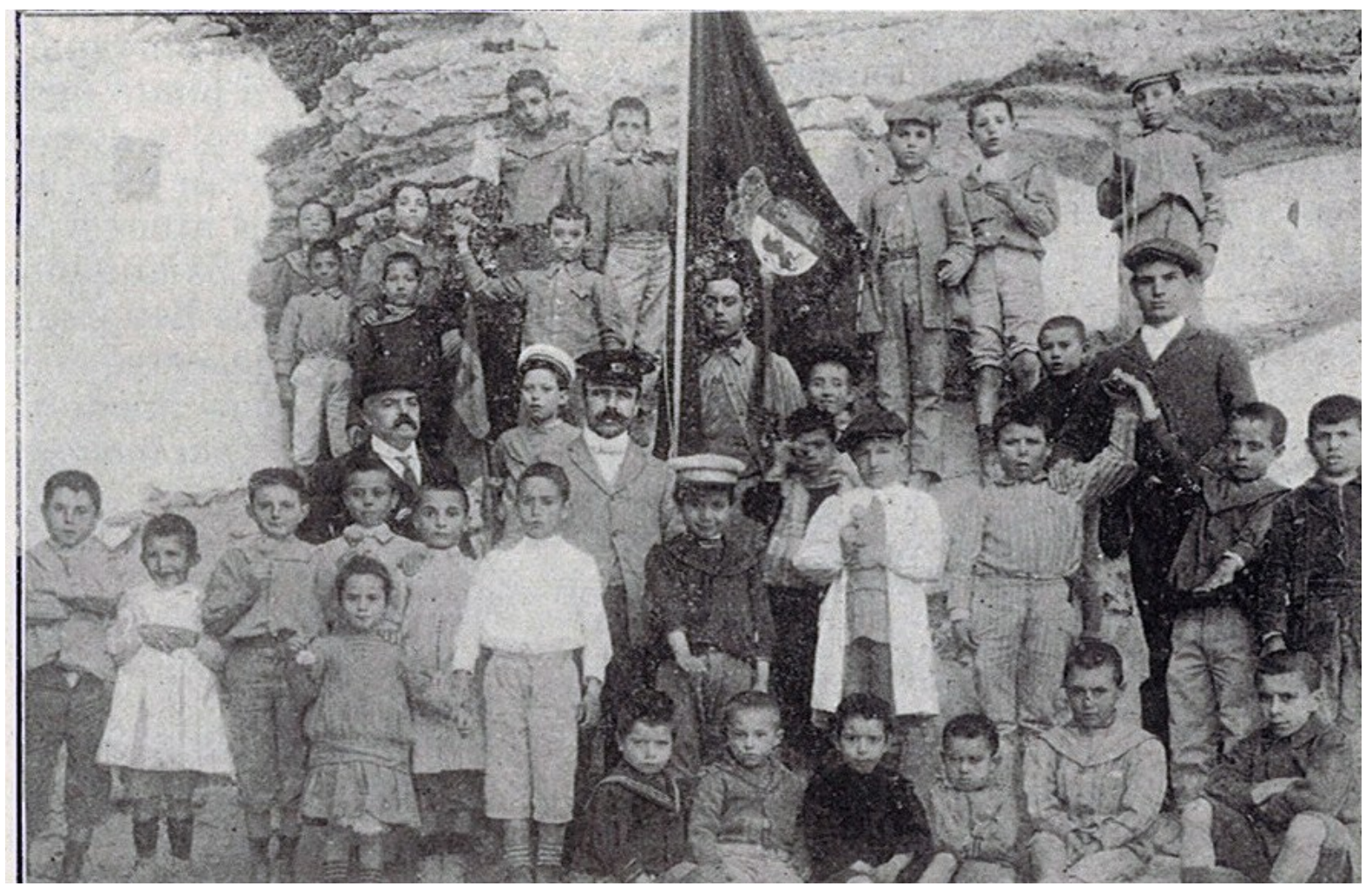

Fuente: Educacionista, n. 10-11-12, dic. 1912 y ene. 1913, p. 15.

En otra fotografía se reproduce a un grupo de alumnas y madres, antiguas estudiantes, de Margarita Carpena. Curiosamente en el pie de foto se dice que la maestra encargó la foto como un premio para sus alumnas, por haber sido aplicadas y buenas estudiantes. Al final del texto de ese pie de foto podemos leer: "Santa educación, bien infundada iqué de bienes y dichas proporcionas a los pueblos!" (Educacionista, n. 6, 10 oct. 1912, p. 3). 
Imagen 3 -

Grupo de alumnas y madres de la maestra Margarita Carpena.

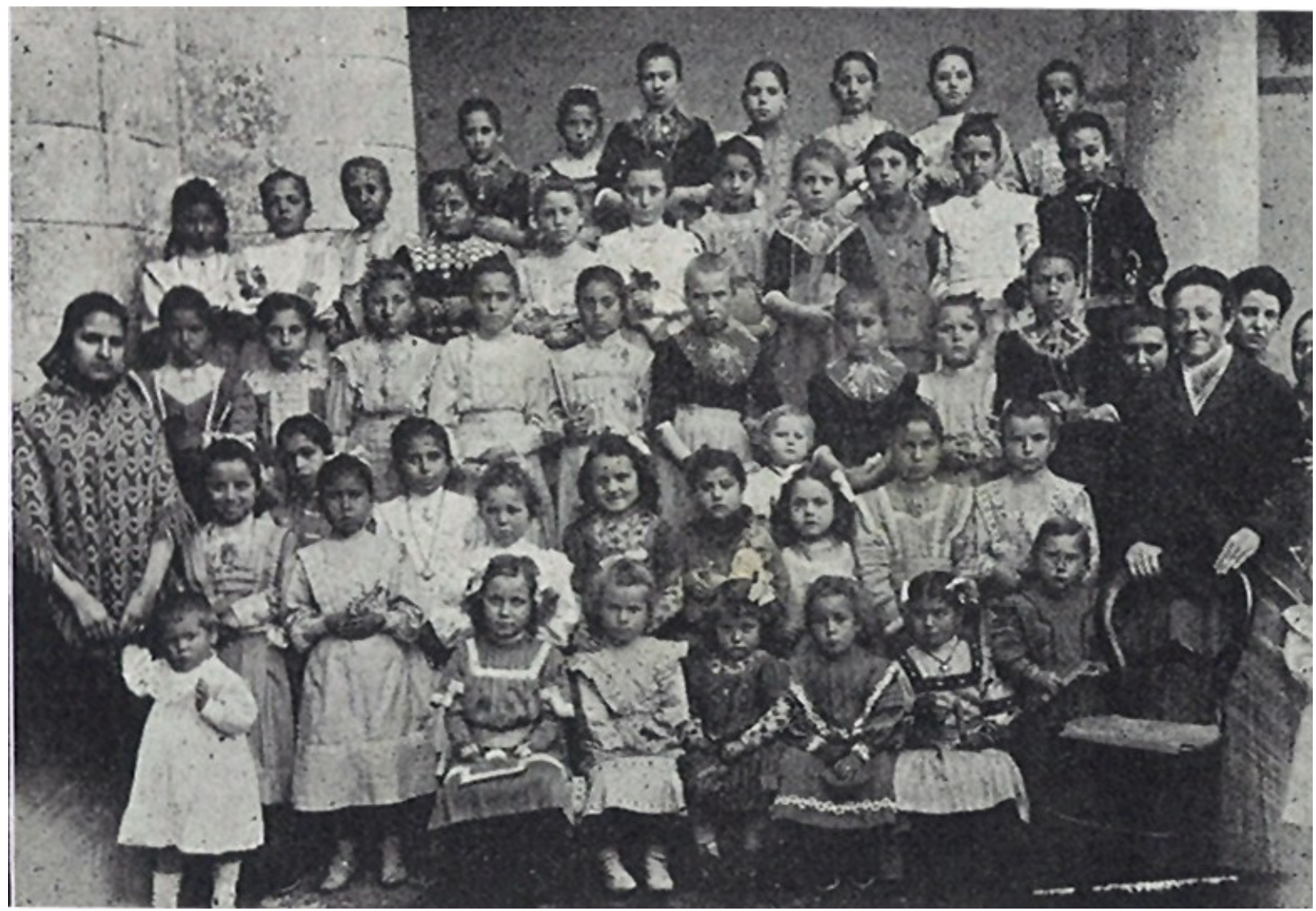

Fuente: Educacionista, n. 6, 10 oct. 1912, p. 3

Un par de fotografías más muestran las dos salas en las que se montó una exposición escolar en 1912. Y una última foto, de entre las seleccionadas aquí para dar sucinta muestra de lo publicado, recoge el escenario en el que había tenido lugar una fiesta escolar en Llucmajor, con la asistencia de alumnos de otras escuelas. Hemos de decir que algunas de las fotografías descritas hasta el momento aparecen también publicadas en la revista Vida Isleña, aspecto que demostraría la trascendencia de las imágenes y los múltiples usos que se dio de las mismas. 
Imagen 4 -

Primer salón de la $1^{\text {a }}$ Escuela nacional de niños de Llucmajor, durante la primera exposición escolar.

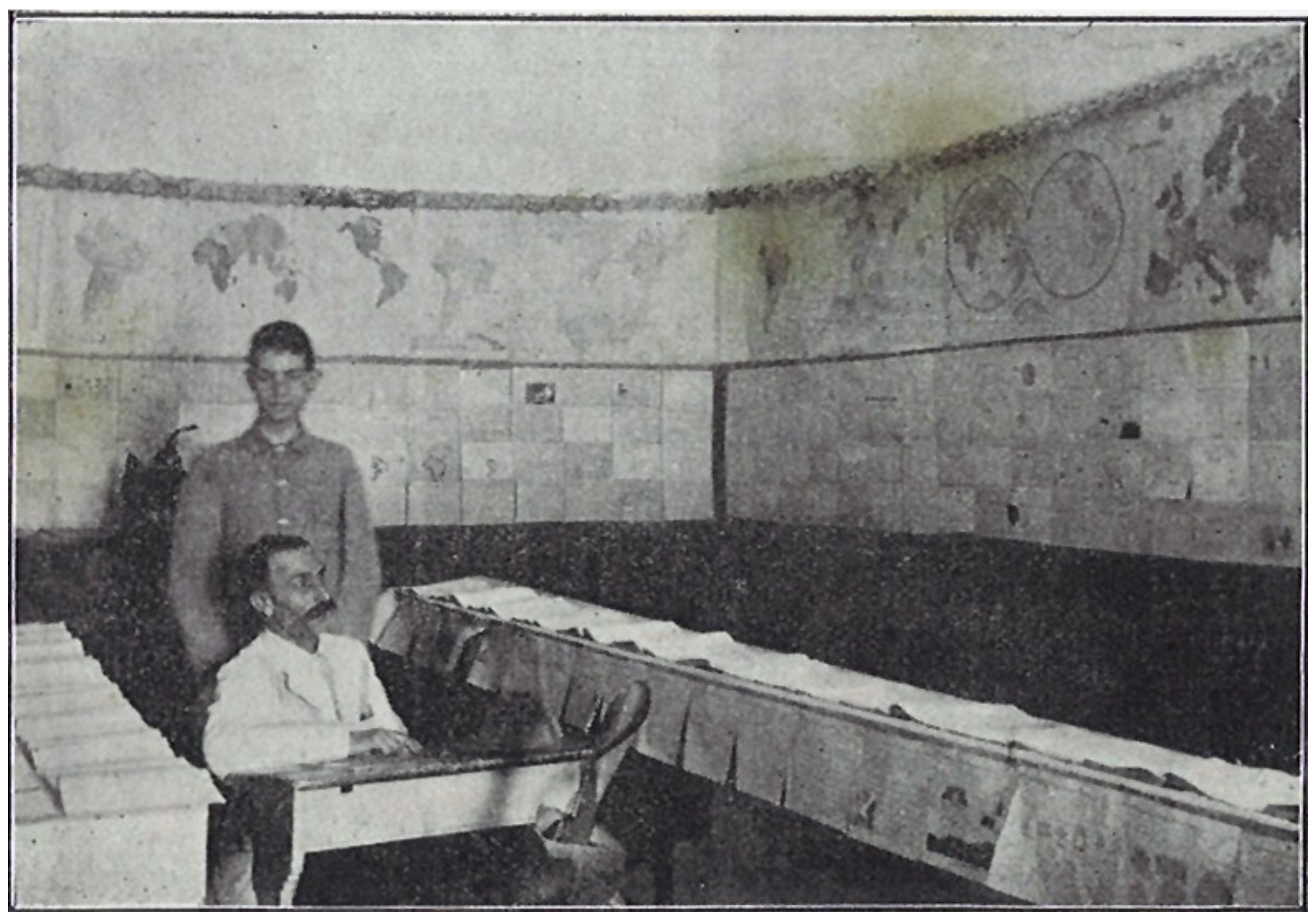

Fuente: Educacionista, n. 6, 10 oct. 1912.

Otro grupo de instantáneas está dedicado al retrato de estudiantes, especialmente en los casos en que éstos resultan premiados por algún mérito académico.

Dentro de las imágenes restantes encontramos, por ejemplo, una fotografía dedicada al monumento a Pestalozzi elevado en Birr con motivo del primer centenario de su nacimiento; una reproducción de una postal en la que un maestro alemán enseña a saludar a sus discípulos; o una tarjeta postal de felicitación al Príncipe de Asturias.

En definitiva, el conjunto de fotografías publicadas en esta revista no sólo acompañan al texto, sino que sirven al mismo tiempo como elemento para reconocer escenarios y prácticas escolares o para reforzar la imagen de los sujetos cuya labor profesional quiere ser resaltada. Tienen pues capacidad de narración ayudando, en definitiva, a transmitir y reforzar el discurso pedagógico de Rufino Carpena Montesinos.

\section{Conclusiones}

Rufino Carpena Mostesinos es un maestro significado en el panorama de la educación española de finales del siglo 19 y primeras décadas del 20. Es un ejemplo prototípico de profesional de la docencia que reivindica su profesión y defiende su prestigio reclamando mejoras profesionales y en las condiciones de trabajo. Lo hace a través de todas las plataformas posibles: artículos en prensa, conferencias, cartas a las 
autoridades e incluso creando, con mucho esfuerzo económico, una publicación ilustrada. En Educacionista, Carpena llega a utilizar un medio muy novedoso en aquella época como la fotografía, para dar visibilidad a sus actividades educativas.

Su discurso pedagógico, que podemos conocer por sus artículos, no es ni mucho menos original, pero nos permite ver cómo reivindica la experiencia y la práctica como fuente para hacer propuestas educativas. Es un discurso al servicio de la construcción de una identidad docente y mediante el cual se aboga por el ejercicio profesional como sustento de la autoridad pedagógica frente a los teóricos que desconocen la práctica y apoyan sus discursos en puras teorías.

Ese mismo discurso se hace patente y se ve reforzado mediante la publicación de Educacionista. Este material, inserto en lo que conocemos como prensa pedagógica, resulta de gran riqueza para el investigador tanto por sus contenidos escritos como visuales - imágenes como mapas y dibujos y el conjunto de fotografías publicadas. No sólo representa la palestra a través de la cual Rufino Carpena expone sus ideas, aspiraciones y proyectos - quizá idealistas, pero con un enorme atractivo - sino también el vehículo a través del cual se convierte a los alumnos en protagonistas, dando así visibilidad, a través de sus trabajos y cartas, a la actividad escolar.

\section{Bibliografía}

ÁVILA FERNÁNDEZ, Alejandro, HOLGADO BARROSO, Juan A. Las conferencias pedagógicas: un instrumento para la formación permanente del magisterio español (siglos 19 y 20). Revista Historia de la Educación Latinoamericana, n. 6, 2014, p. 23-38.

BOTREL, Jean-François. Naissance et essor d'une maison d'édition scolaire: La Casa Hernando de Madrid 1828-1883. In: VV. AA., Libres et libraires en Espagne et au Portugal (XVle-20e siècle). Paris: CNRS, 1989, p. 111-144.

CARPENA, Rufino. Conferencias pedagógicas. La Escuela Moderna, $1^{\circ}$ feb. 1892, p. 114117.

CARPENA, Rufino. Nomenclator escolar. Madrid: vda. De Hernando, 1896.

CARPENA, Rufino. Textos de enseñanza. El Magisterio Balear, 17 nov. 1900.

CARPENA, Rufino. Después de una explicación. El Magisterio Balear, 31 jan. 1901.

CARPENA, Rufino. Ocurrencias pedagógicas: caos y cosas, recursos, procedimientos, etc. El Magisterio Balear, 10 abr. 1901.

CARPENA, Rufino. Asociación benéfica denominada Lectores Murenses de la Villa de Muro (Baleares): Fundada por Don Rufino Carpena Montesinos. Palma: Tipo-Lit. de Bartolomé Rotger, 1902.

CARPENA, Rufino. La enseñanza vivida. El Magisterio Balear, 13 abr. 1912.

CARPENA, Rufino. Vida hermosa en poblados modernos: Sistema Carpena - novela semi-històrica que encierra un proyecto de aplicación y beneficio mundial. Barcelona: Miret, 1926.

COLOM CAÑELLAS, Antoni Joan. Joan Capó Valls de Padrinas: un temps, uns fets. Palma: Universitat de les Illes Balears, 1993.

COLOM, Antoni Joan; DÍAZ, Francisco. Educación y sociedad en la Mallorca contemporánea. Palma: Caja de Ahorros de Colonia-Pollensa, 1977. 
COMAS RUBÍ, Francesca, SUREDA GARCIA, Bernat. La premsa pedagògica en la construcció de la identitat professional dels mestres: El Magisterio Balear. Educació $i$ Història: Revista d'Història de l'Educació, n. 24, 2014, p. 51-68.

COMAS RUBÍ, Francesca, SUREDA GARCIA, Bernat. Photography and advertising of the Maria Montessori method in Spain (1911-1931). Paedagogica Historica, v. 48, n. 4, 2012, p. 571-587.

GARCERÁN AULET, Rafael. La herencia institucionista y la enseñanza activa en Mallorca. La labor de: Miquel Porcel i Riera, Rufino Carpena Montesinos, Joan Montserrat i Parets y Melchor Daviu i Matas. Educació i Cultura. Revista Mallorquina de Pedagogia, n. 18,2005 , p. 53-75.

GARCERÁN AULET, Rafael. La escuela de los socialistas de Llucmajor (1909-1915). Educació i Cultura. Revista Mallorquina de Pedagogia, n. 12, 1999, p. 87-101.

JAUME I CAMPANER, Miquel. Antecedents de Freinet a les Illes Balears. Bolletí de la Societat Arqueològica Lul-liana: Revista d'estudis històrics, n. 66, 2010, p. 183-210.

LLINARES MARTORELL, Josep. La tasca pedagógica de la familia Carpena Montesinos a Muro. Algebelí, n. 132, 1985, p 18-19.

PAYERAS COLL, Pedro. Miguel Porcel y Riera (1869-1933): manuales escolares cíclicos y activismo escolar. Madrid: Uned, 2008

SALAS VIVES, Pere. Guillem Cifre de Colonya (1852-1908): un sant que no anava a missa. Pollensa: El Gall, 1999.

SUREDA GARCÍA, Bernat. La producción y difusión de los manuales escolares. In: Escolano, Agustín (dir.), Historia ilustrada del libro escolar en España: del Antiguo Régimen a la Segunda República. Madrid: Fundación Germán Sánchez Ruipérez y Ediciones Pirámide, 1997, p. 69-100.

SUREDA GARCÍA, Bernat; GONZÁLEZ GÓMEZ, Sara. Educacionista, una publicación escolar pionera (1912-13). In: Hernández Díaz, José María (coord.). La prensa de los escolares y estudiantes: su contribución al patrimonio histórico educativo. Salamanca: Universidad de Salamanca, 2015, p. 221-231.

TERRÓN, Aida. El movimiento asociacionista del magisterio nacional: orígenes y configuración histórica. Historia de la Educación. Revista interuniversitaria, n. 6, 1987, p. 279-300.

VIÑAO FRAGO, Antonio. Innovación pedagógica y racionalidad científica: la escuela graduada en España (1898-1936). Madrid: Akal, 1990.

BERNAT SUREDA GARCÍA es doctor en Pedagogía. Es Catedrático de la Universidad de las Islas Baleares - UIB -, director del Departamento de Pedagogía y Didácticas Específicas de la UIB y del Grupo de Estudios de Historia de la Educación del Instituto de investigación e innovación educativa de la UIB. Es director de la revista Educació i Història. Ha dirigido diversos proyectos de investigación financiados por organismos públicos en convocatorias competitivas y actualmente es investigador principal de uno sobre fotografía e historia de la educación.

Dirección postal: Facultad de Educación. Carretera de Valldemossa, km 7,5 07122 - Palma - Islas Baleares - España.

E-mail: bernat.sureda@uib.es. 
SARA GONZÁLEZ GÓMEZ es doctora en Ciencias de la Educación por la Universidad de Salamanca - Usal - y profesora del Departamento de Pedagogía y Didácticas específicas de la Universidad de las Islas Baleares - UIB. Es miembro del Grupo de Estudios de Historia de la Educación - Irie/UIB y del grupo de investigación reconocido Memoria y proyecto de la educación - Usal. Es coeditora de las revistas Espacio, Tiempo y Educación y Foro de Educación y pertenece al equipo editorial de Educació i Història.

Dirección postal: Facultad de Educación - Carretera de Valldemossa, km 7,5 07122 - Palma - Islas Baleares - España.

E-mail: sara.gonzalez@uib.es.

Recebido em 16 de dezembro de 2015.

Aceito em 27 de agosto de 2016. 